\title{
Automatically Predicting Information Quality in News Documents
}

\author{
Rong Tang \\ School of Information \\ Science and Policy \\ University at Albany \\ 135 Western Avenue \\ Albany, NY 12222 \\ tangrealbany $\cdot$ edu
}

\author{
Kwong Bor Ng \\ Graduate School of \\ Library and Information \\ Studies, Queens \\ College, CUNY. \\ New York, NY 11367 \\ kbng@qc .edu
}

\author{
Tomek Strzalkowski \\ ILS Institute \\ Univerity at Albany \\ 1400 Washington Ave \\ Albany, NY 12222 \\ tomekealbany.edu
}

\author{
Paul B. Kantor \\ School of Communication \\ Information and Library \\ Studies \\ Rutgers University \\ New Brunswick, NJ 08901 \\ kan- \\ torescils.rutgers.e \\ du
}

\begin{abstract}
We report here empirical results of a series of studies aimed at automatically predicting information quality in news documents. Multiple research methods and data analysis techniques enabled a good level of machine prediction of information quality. Procedures regarding user experiments and statistical analysis are described.
\end{abstract}

\section{Introduction}

As a part of a large-scale multi-institutional project HITIQA (High-quality Interactive Question Answering), we worked on developing an extended model for classifying information by quality, in addition to, and as an extension of the traditional notion of relevance. The project involves Computer and Information Science researchers from University at Albany and Rutgers University. Our serving clientele are intelligent analysts, and the documents that we targeted were news articles.

\section{Research Approach}

The term "Quality" is defined by International Organization of Standards (1986) as "the totality of characteristics of an entity that bear on its ability to satisfy stated and implied need" (Standard 8402, 3.1). Among numerous study on classification of information quality, Wang and Strong (1996) proposed four dimensions of qualities as detailed in Table 1: intrinsic, contextual, representational, and accessibility.

\begin{tabular}{ll}
\hline Categories & Elements \\
\hline Intrinsic IQ & $\begin{array}{l}\text { Accuracy, Objectivity, Believ- } \\
\text { ability, Reputation }\end{array}$ \\
\hline Accessibility IQ & Accessibility, Security \\
\hline Contextual IQ & $\begin{array}{l}\text { Relevancy, Value-added, } \\
\text { Timeliness, Completeness, }\end{array}$ \\
& Amount of Information \\
\hline $\begin{array}{l}\text { Representa- } \\
\text { tional IQ }\end{array}$ & $\begin{array}{l}\text { Interpretability, Ease of Under- } \\
\text { standing, Concise Representa- } \\
\text { tion, Consistent Representation }\end{array}$ \\
\hline
\end{tabular}

Table 1. Information Quality Dimensions (Source: Strong, Lee, Wang, 1997, p.39)

Empirical attempts to assess quality have primarily focused on counting hyperlinks in a networked environment. Representative studies include the work by Amento and his colleagues (Amento, Terveen, \& Hills, 2000), Price and Hersh (1999), and Zhu and Gauch (2000). However, as a whole, previous studies were only able to produce algorithmic measures for Web documents based on link counts and with a limited number of quality aspects such as popularity. Our approach is to record actual users' quality assessments of news articles and conduct advanced statistical models of association between users' quality scoring and occurrence and prevalence of certain textual features.

\section{Methodology and Results}

Multiple research methods were used. Firstly, we conducted focus-group sessions to elicit key quality aspects from news analysts. Secondly, we performed experts and students quality judgment experimental sessions. Thirdly, we identified a set of textual features, ran programs to generate counts of the features, and performed statistical analysis to establish the correlation between features and users' quality ratings. 
Two focus group sessions were conducted during March and April of 2002. Participants included journalism faculty members, professional editors, and a number of journalists from a local newspaper Albany Times Union. Nine information quality criteria were considered to be salient to the context of news analysis: Accuracy, Source reliability, Objectivity, Depth, Author credibility, Readability, Conciseness, Grammatically Correctness, and Multiple Viewpoints.

A computerized quality judgment system that incorporated the nine quality aspects was developed. One thousand medium-sized (100 to 2500 words) news articles were selected from the TREC collection (Voorhees, 2001) with 25 relevant documents each from five TREC Q\&A topics.

We recruited expert and student participants for judgment experiments. Expert sessions were performed first and ten documents judged by experts were selected and used as the training and testing material for the student participants. The entire judgment experiment period ran from May to August of 2002. As a result, each of the 1,000 documents was rated twice, by two different judges, one at Albany, and one at Rutgers.

There were high inter-judge agreements between Albany and Rutgers. Figure 1 is the normality plot of the difference between scores assigned by Rutgers' judges and Albany's judges on the variable of "accuracy," with a mean almost equals to zero (with range from -9 to + 9 ). The curves of the other eight quality variables are similar to the one below, indicating a very insignificant disagreement in judgments.

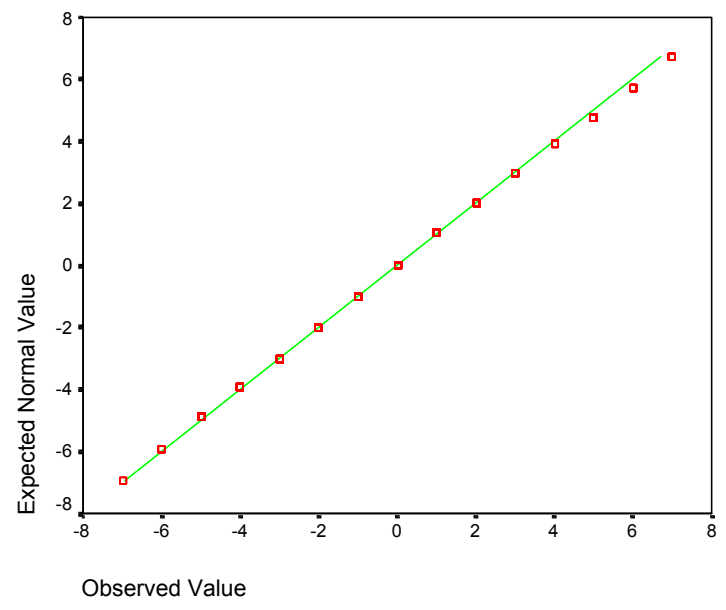

Figure 1. Normality Plot of differences in quality judgments on the aspect of "Accuracy"

Principle component analysis (PCA) revealed the same two components from Albany data as from Rutgers data. As shown in Figure 2, one component (the lower one) consists of "credibility", "source reliability", "accuracy", "multi-view", "depth", and "objectivity."
The second component (the upper one) consists of "grammar", "readability", and "verbose and conciseness". Together they explain $58 \%$ of the variance.

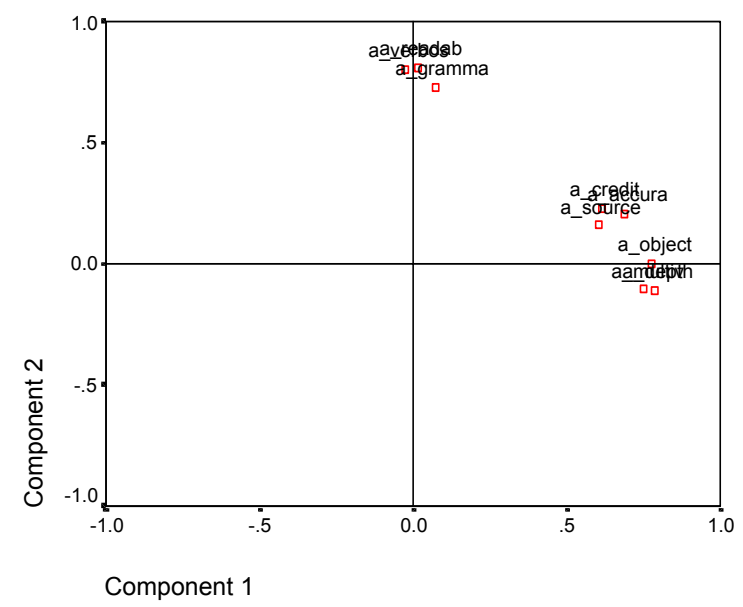

Figure 2. PCA of Judgment data, in rotated space. Rotation method: Oblimin with Kaiser Normalization. Rotation converged in 5 iterations.

We recoded users' scores 1 to 5 as low and scores 6 to 10 as high. We split the 1,000 documents into two halves by random selection. In our training round the first half was used to estimate the parameters that would give best discriminant and logistic regression functions. In our testing round, we applied the functions to the other half to predict the quality criteria of the documents.

\begin{tabular}{lcc}
\hline & $\begin{array}{l}\text { Discriminant } \\
\text { Analysis Cor- } \\
\text { rect-Rate }\end{array}$ & $\begin{array}{l}\text { Logistic } \\
\text { Regression } \\
\text { Correct-Rate }\end{array}$ \\
\hline Accuracy & $75.8 \%$ & $75.9 \%$ \\
\hline Source Reliability & $67.8 \%$ & $68.5 \%$ \\
\hline Objectivity & $70.6 \%$ & $73.8 \%$ \\
\hline Depth & $77.4 \%$ & $77.9 \%$ \\
\hline Author Credibility & $69.3 \%$ & $71.7 \%$ \\
\hline Readability & $81.3 \%$ & $83.0 \%$ \\
\hline Conciseness & $70.5 \%$ & $70.9 \%$ \\
\hline Grammar & $74.9 \%$ & $75.1 \%$ \\
\hline Multi-view & $82.1 \%$ & $82.2 \%$ \\
\hline Table 2. Perfor
\end{tabular}

Table 2. Performance of prediction (based on splithalf training and testing) by two methods

We then employed stepwise discriminant analysis to select the dominant predictive variables from a range of 104 textual features. These features included elements of punctuations, special symbols, length of document segments, upper case, quotations, key terms, POS, and entities. Our further analysis suggested that certain text features are highly correlated with each of the nine aspects. 


\begin{tabular}{llc}
\hline $\begin{array}{l}\text { Quality As- } \\
\text { pects }\end{array}$ & Textual Feature & $\begin{array}{c}\text { Pearson } \\
\text { correlation } \\
(2 \text { tails })\end{array}$ \\
\hline Accuracy & Personal Pronoun & 0.0002 \\
\hline Source & Distinct organization & 0.0048 \\
\hline Objectivity & Pronoun & 0.0001 \\
\hline Depth & Document length & 0.0000 \\
\hline $\begin{array}{l}\text { Author } \\
\text { Credibility }\end{array}$ & $\begin{array}{l}\text { Date unit, e.g. day, } \\
\text { week }\end{array}$ & 0.0000 \\
\hline Readability & Closing parenthesis & 0.0099 \\
\hline Conciseness & $\begin{array}{l}\text { Subordinating prepo- } \\
\text { sition or conjunction }\end{array}$ & 0.0003 \\
\hline Multi-view & Past tense verb & 0.0000 \\
\hline $\begin{array}{l}\text { Grammatical } \\
\text { correctness }\end{array}$ & $\begin{array}{l}\text { Average length of } \\
\text { paragraph in words }\end{array}$ & 0.0016 \\
\hline
\end{tabular}

Table 3. Highly correlated textual features and quality aspects

At this point, we are able to produce good prediction of several aspects of information quality, including Depth, Objectivity, Multi-view, and Readability. The prediction testing and training for the remaining quality aspects are currently in progress. Tables 4 and 5 illustrate the results of training versus testing classification for the criteria of "objectivity" and "depth," with ratings grouped into high and low categories.

\begin{tabular}{|c|c|c|c|c|}
\hline \multirow{2}{*}{\multicolumn{3}{|c|}{ Objectivity }} & \multicolumn{2}{|c|}{$\begin{array}{l}\text { Predicted Group } \\
\text { Membership }\end{array}$} \\
\hline & & & Low & High \\
\hline \multirow{2}{*}{$\begin{array}{l}\text { Training } \\
\text { Cases }\end{array}$} & \multirow{2}{*}{ Original } & Low & $58.7 \%$ & $41.3 \%$ \\
\hline & & High & $12.7 \%$ & $87.3 \%$ \\
\hline \multirow{2}{*}{$\begin{array}{l}\text { Testing } \\
\text { Cases }\end{array}$} & \multirow{2}{*}{ Original } & Low & $45.5 \%$ & $54.5 \%$ \\
\hline & & High & $23.5 \%$ & $76.5 \%$ \\
\hline
\end{tabular}

Table 4. Classification result of "objectivity." $75.5 \%$ of training cases correctly classified, $63.5 \%$ of testing cases correctly classified

\begin{tabular}{|c|c|c|c|c|}
\hline \multirow[t]{2}{*}{ Depth } & & & \multicolumn{2}{|c|}{$\begin{array}{l}\text { Predicted Group } \\
\text { Membership }\end{array}$} \\
\hline & & & Low & High \\
\hline \multirow{2}{*}{$\begin{array}{l}\text { Training } \\
\text { Cases }\end{array}$} & \multirow[t]{2}{*}{ Original } & Low & $64.5 \%$ & $35.5 \%$ \\
\hline & & High & $11.9 \%$ & $88.1 \%$ \\
\hline \multirow{2}{*}{$\begin{array}{l}\text { Testing } \\
\text { Cases }\end{array}$} & \multirow[t]{2}{*}{ Original } & Low & $51.0 \%$ & $49.0 \%$ \\
\hline & & High & $22.6 \%$ & $75.4 \%$ \\
\hline
\end{tabular}

Table 5. Classification result of "depth." $74.5 \%$ of training cases correctly classified, $61.6 \%$ of testing cases correctly classified

\section{Summary}

In this study, we were able to identify important quality criteria relevant to intelligent analysts' work and we were also able to generate automatic quality metrics of news documents using users' quality judgments. Our next step is to apply our machine prediction method to produce measures of a new set of documents and have users to verify and modify machines' scoring. We hope that through this, we can collect new data to test our quality metrics and to further improve its' performance.

\section{Acknowledgement}

This paper is based on work supported by the Advanced Research and Development Activity (ARDA)'s Advanced Question Answering for Intelligence (AQUAINT) Program under contract number 2002H790400-000.

\section{References}

Amendo, B., Terveen, L., \& Hill, W. (2000). Does "authority" mean quality? Predicting expert quality ratings of Web documents. Proceedings of the TwentyThird Annual International ACM SIGIR Conference on Research and Development in Information Retrieval, 296-303.

Price, S. L., \& Hersh, W. R. (1999). Filtering Web pages for quality indicators: An empirical approach to finding high quality consumer health information on the World Wide Web. Proceedings of the AMIA 1999 Annual Symposium. 911-915.

Voorhees, E. (2001). Overview of TREC 2001. In E. Voorhees (ed.) NIST Special Publication 500-250: The Tenth Text REtrieval Conference, pp. 1 - 15. Washington, D.C.

Strong, D., Lee, Y., \& Wang, R. Y. (1997). 10 potholes in the road to information quality. IEEE Computer, 30(8), 38-46.

Wang, R. Y., \& Strong, D. M. (1996). Beyond accuracy: What data quality means to data consumers. Journal of Management Information Systems, 12(4), 5-34.

Zhu, X., \& Gauch, S. (2000). Incorporating quality metrics in centralized/distributed information retrieval on the World Wide Web. Proceedings of the TwentyThird Annual International ACM SIGIR Conference on Research and Development in Information Retrieval, 288-295. 